\title{
Not Commanding but Persuading and Shaping that Make a Learning Organization
}

\author{
Sammy Kristamuljana \\ Department of Strategic Management, Prasetiya Mulya Business School \\ Jakarta, Indonesia \\ sammyk@pmbs.ac.id
}

\begin{abstract}
- generating a willingness to learn from an individual is not a straightforward task. The same applies to an organization which is a group of people that collectively try to achieve mutual and agreed objectives. Consequently, the strategic leaders who initiate the learning process should raise the "sense of urgency" inside the mind of the candidate learning partners at first as the main source of the need to shape their company to be a learning organization. In this respect the sense of urgency is: "The raising of energy within the strategic leaders so they committed to save their company". Secondly, the strategic leaders should continuously embed and develop learning and can-do attitude of the learning partners. Thirdly, the strategic leaders together with the learning partners should from time-totime evaluate the learning result by measuring the learner's firm competitiveness in the market. The current change in business landscape into the digital era has demanded organizations further to be a learning organization, particularly to have an ability to learn fast so that it can take the benefits of the first mover advantage. Based on the experience of many companies in the past twenty five years, they suggested that commanding people does not make a learning organization. Instead, it is by persuading and shaping that create a learning organization. Hence, strategic leaders can also identify the effective methods to persuade and to shape the companies to be a learning organization. The identified methods consist of three. Firstly, the strategic leaders who offer a high value challenge which is difficult to be turned down by the candidate of learning partners. Secondly, the learning partners are always accompanied by the strategic leaders. Thirdly, the strategic leaders continuously inspire the learning partners to actively seek for breakthrough which creates value. The result of this study suggested some research questions as a starting point for further research.
\end{abstract}

Keywords-Business landscape, learning organization, sense of urgency, persuading, shaping, commanding, high value challenge, accompaniment, continuous value creation, digital era.

\section{Introduction - Sense Of URgency That Leads To The} NEED Of LEARNING ORGANIZATION

Many business practitioners have an eagerness to shape their companies to be a learning organization after reading The Learning Organization [1] and obtaining ideas from The Single-Loop and Double-Loop Learning [2] as shown for example in a publication at The Learning Organization [3]. However, desire is not the same thing as need since both reflect two different meanings. A need will be desperately obtained and, if unobtainable, people will seek for a substitute. Desire, on the other hand, has a short-term nature and will be forgotten once it is not fulfilled.

Much of the organizational experience implied that a need to shape a company into a learning organization was a result of the sense of urgency towards achieving corporate sustainability [4]. The following are three examples of companies which were able to shape itself into a learning organization after triggered by the sense of urgency that it needs to survive:

\section{Toyota Motor USA.}

Early 1990s for Toyota was the period that marked the emergence of needs to become a learning organization. The sense of urgency occurred as the result of The US Government regulation and policy which prohibited all Japanese car manufacturers in USA to import spare parts from abroad. Specifically, manufacturers - including Toyota - were required to use local spare parts supplier. Consequently, Toyota Motor USA established Toyota Supplier Support Center (TSSC) unit, which consisted of people who were able to convince local suppliers to apply lean manufacturing as the main requirement to be a supplier of Toyota spare parts. Toyota, as the same global car manufacturer as others, obtained spare parts supplies from spare parts manufacturers to assemble cars that Toyota produced. However, having a local spare part supplier which is able to supply Toyota with high quality spare parts and competitive price is not a simple task. Besides the limited number of suppliers, such quality criteria and pricing could only be obtained if the supplier applies Toyota's lean manufacturing [5].

\section{Procter \& Gamble (P\&G)}

Tuesday, July the sixth of 2000 marked the emergence of $P \& G$ 's sense of urgency to be a learning organization. The sense of urgency was felt by A.G. Lafley himself who, on that day, was appointed as the CEO of $P \& G$ due to the sudden resignation of preceding CEO. The $P \& G$ share price had been in free fall by more than $50 \%$ in the past six months since January 2000, which means that shareholders had suffered losses of more than $\$ 50$ billion. Facing such situation, A.G. responded quickly by calling key strategic leaders of $P \& G$ individually and convinced them to stay in the company. His action was decisively correct, considering the recent change 
on P\&G's organizational structure, from worldwide geographic area to be a newly established worldwide product divisional. The new structure required innovative strategic leaders who already had deep knowledge and expertise on a new product development and market on each geographic area. As situation had become more stable, A.G. multiplied the number of product innovation teams which operated across functions - making $P \& G$ an innovative organization with innovative products [6].

\section{Companies in the Digital Era}

The global economic outlook which has not reflected significant improvement since subprime mortgage crisis in $2007 / 2008$, and the effect of mass adoption of digital technology, has increased the needs for companies to be a learning organization. What has been stated by a strategy guru [7] more than thirty years ago that companies will compete not only with its competitors, but also with the customers, suppliers, new entrants, and substitute products have become far more visible nowadays. To be precise, companies are currently facing the threat of disruptive technology adoption by those "five" competitors, whereas in the same time they also have an opportunity to adopt disruptive technology to overcome its five competitors [8]. Due to the widely adopted principle of 'learn quickly to produce quicker than the others', there has been an increasing needs of assigning a Chief Digital Officer (CDO) position [9] [10]. If Chief Information Officer (CIO) is the provider of technology-based information needs, $\mathrm{CDO}$ is the transformer of the whole corporate organization with responsibility ranging from explaining the latest trend of digitization inside and outside the company, to building new digital-based businesses which are completely new.

\section{Methodology - THE CHARACTERISTICS OF STRATEGIC LEADERS AND EFFECTIVE LEARNING METHODS}

The aforementioned examples suggest that the emergence of needs to shape a company to be a learning organization are diverse - by the type of urgency that triggered the needs, the position of the learning organization champions or strategic leaders or organizational actors [11] within an organization, time period, and the intensity of competition. However, the analysis of the most influential strategic leader characteristics and methods that are used to establish a learning organization have several common similarities.

By using the idea of Power and Influence Levers [12] as seen on Exhibit 1, it can be concluded that strategic leaders have the following characteristics:

- Firstly, the strategic leaders use persuading method in convincing parties which are invited to establish a learning organization. Involved parties in this case are local spare parts suppliers in Toyota Motor USA case, the key strategic leaders of $P \& G$, and CEO and other top management personnel in the case of companies in digital era.

- $\quad$ Secondly, strategic leaders rely on the shaping ability to shape corporate culture [13] - from previously uncomfortable and unwilling to learn, to be ultimately having a culture of learning. The shaping requires a high discipline process and consistency, and takes a longer time period. Until 2001, Toyota Motor USA had been implementing the process for about ten years. A.G. Lafley of $\mathrm{P} \& \mathrm{G}$ had also required the same period of time. The CDO of companies in the digital era are predicted to need at least the same period too.

Fig. 1. Power and Influence Levers

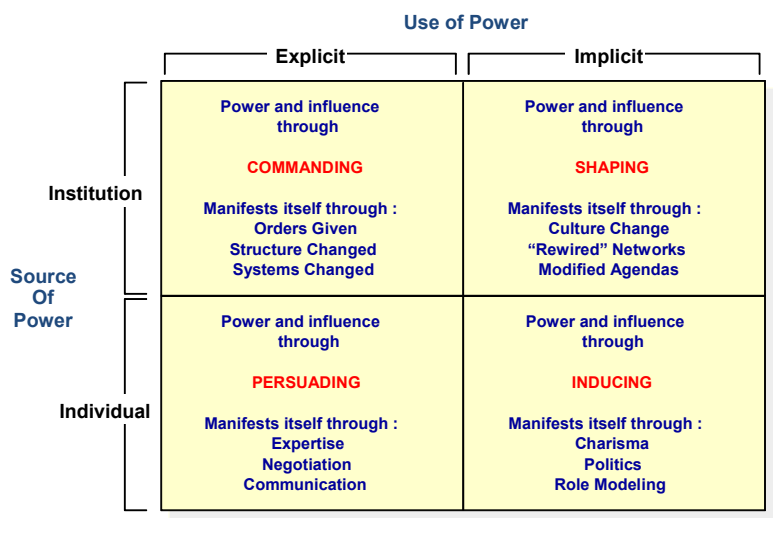

- Thirdly, it appears that commanding is not used when companies are trying to convince parties in establishing a learning organization. This makes sense since local spare parts, the key strategic leaders of $P \& G$, and CEO and other top management personnel are not subordinate of $\mathrm{CDO}$ - they are in fact learning partners. Shaping a new culture requires direct involvement whereas commanding is aimed to avoid direct involvement.

\section{RESUlts AND Discusssion}

Accompanying the use of the Power and Influence Levers, strategic leaders applied three methods to convince partners to be involved in learning activities:

1. Offering a high value challenge which is difficult to be turned down. In the case of Toyota, the challenge is the fact that partner companies will produce a high quality spare-part with low production cost if they are willing to apply lean manufacturing. In the $P \& G$ case, the challenge is to achieve an exponential increase of revenue generated by inorganic growth of a new innovative product and an organic growth of existing products. For companies in the digital era, the presence of CDO will change the nature of the company - from conventional type of firm to be a fully digital firm. Consequently, the company can operate in more efficient and effective ways and ultimately it will trigger new business ideas and opportunities in the digital era.

2. Accompanying the partner in shaping them into a learning organization, Toyota Motor USA positioned itself as the permanent partner so that their partner companies can master and apply lean manufacturing in its operational core. With A.G. Lafley serving as the CEO, the objective to make $\mathrm{P} \& \mathrm{G}$ as an innovation-based and product-based learning 
organization will be more guaranteed to be achieved. In companies in the digital era the presence of CDO is essentially intended to accompany fellow directors to change the operation to be digital and collectively explore the new digitalbased business opportunities.

3. Continuously moving with agile movement in seeking breakthrough which creates values. The continuous improvement principle of Toyota - which states that today is better than yesterday and tomorrow will be better than today indicates that Toyota Motor USA and its partners are continuously moving to seek for breakthrough which creates values. The same spirit is reflected in $P \& G$ case by means of diverse attempts of market penetration through new product and business innovation to realize organic and inorganic growth. CDO of the companies in the digital era can only show their values by showing agile movement in changing existing conventional operations into digitized companies and creating new digital businesses.

\section{CONCLUSION}

The analysis of the three types of company above is based on the notion that the sense of urgency is the main source of the need to shape a company to be a learning organization. By taking into account the drawbacks, this analysis is successful in identifying the most suitable power and influence levers which are used by strategic leaders in shaping his/her company to be a learning organization. In fact, the success of shaping a learning organization is more determined by their capabilities in persuading and shaping, not commanding. Nevertheless, the result of this identification might be considered too simple and it needs to wait for further research to further strengthen or falsify.

On the other hand, this analysis successfully identified the three effective methods to invite partners in shaping their companies to be a learning organization. The process of establishing the learning organization can be smoothly performed due to the fact that strategic leaders initially offered a high value challenge which is difficult to be turned down by the candidate of business partners. Furthermore, the learning partners are always accompanied by the strategic leaders who never run out of inspiration to support them to actively seek for breakthrough which creates value.

The experience of Toyota Motor USA and A.G. Lafley at P\&G were already written as a history. However, the current and future role of Chief Digital Officer (CDO) at companies in the digital era will be still discussed further in the case of processing the big data for example [14]. Hence, the questions such as "Are persuading and shaping still relevant for CDOs compared to commanding in changing a company to be a learning organization? "Are the three methods to convince partners in changing their companies to be learning organization still relevant? Are there any other methods?" are worthy to be the starting point for further research.

\section{References}

[1] P.M. Senge, The Fifth Discipline: The Art and Practice of Learning Organization. New York: Doubleday/Currency, 1990.

[2] C. Argyris and D. Schon, Organizational Learning: A Theory of Action Perespective. Reading, MA: AddisonWesley, 1978.

[3] V. Bagodi and B. Mahanty, "Double loop learning in the Indian twowheeler service sector",The Learning Organization, vol. 20(4/5), pp 264-278, 2013.

[4] S. Kristamuljana, "The resultant model of strategic management", International Journal on GSTF Business Review, 1(1), pp. 128-131, August 2011.

[5] Asian Wall Street Journal (AWSJ), "Why Toyota wins such high marks on quality surveys", March 16-18, 2001, pp.1,5.

[6] A.G. Lafley and R. Charan, The Game Changer: How you can drive revenue and profit growth with innovation. New York: Crown Business, 2008.

[7] M.E. Porter, Competitive Strategy: Techniques for Analyzing Industries and Competitors. New York: The Free Press, 1980.

[8] S. Kristamuljana, "Navigasi perusahaan era digital", Forum Manajemen Prasetiya Mulya, 29(1), pp. 13-17, Juli-Agustus 2015.

[9] T. Rickards, K. Smaje, and V. Sohoni, "Transformer in chief: The new chief digital officer", McKinsey \& Company, Insights \& Publications, September 2015 .

[10] R. Grossman and J. Rich, "The rise of the chief digital officer", Russell Reynolds Associate 2015 http://www.russellreynolds.com/insights/thought-leadership/the-rise-ofthe-chief-digital-officer

[11] A. Ortenblad, "Towards increased- relevance: context-adapted models of the learning organizations", The Learning Organization, Vol. 22(3), pp. 163-181, 2015.

[12] A. Miller. Strategic Management. Third edition. McGraw-Hill, 1998, pp.426.

[13] L.F. Ford, The Fourth Factor: Managing The Corporate Culture. Indianapolis: Dog Ear Publishing, 2008.

[14] A. Vera-Baquero, R.C. Palacios, V. Stantchev, and O. Molloy, "Leveraging big-data for business process analytics", The Learning Organization, Vol. 22(4), pp. 215-228, 2015. 